\title{
Regional methods for shallow landslide hazard evaluation: a comparison between Italy and Central America
}

\author{
D. Brambilla, L. Longoni \& M. Papini \\ Politecnico di Milano, Department of Environmental, Hydraulic, \\ Infrastructures and Surveying Engineering, Italy
}

\begin{abstract}
Landslides are a serious issue in the Latin American and Caribbean region, causing disasters and casualties every year. Since these regions suffer from endemic poverty and few resources can be allocated for civil protection, the need to maximize results is strong. In order to diminish vulnerability and increase effectiveness of any intervention, a wide knowledge of territory critical situations needs to be achieved. This paper suggests two useful tools to build hazard maps of a chosen territory; these maps can be useful as a Decision Support System (DSS) to help the management of economical resources and to identify the situations that have the greatest need. The two methods proposed are Stability Index MAPping (SINMAP) and the Mora and Vahrson method. Both methods start from the digital terrain model and other various parameters, linked mainly to slope lithology and rainfalls, and obtain a map of the relative hazard from shallow landslides. The methods have been applied to two study cases: one in Guatemala, a perfect example of what has been mentioned about the difficult Central American situation, and one in the Varese district in Italy, a well known site which provides plenty of data and information that was useful to the authors for rigorous testing of methods. Finally the results have been compared, highlighting the strong influence of input data quality on results and the interesting potential of the tested methods; these proved to be successful when input data have enough resolution and to be useful as a DSS in order to identify critical areas and intensify efforts in these areas.

Keywords: shallow landslides, Central America, Stability Index MAPping (SINMAP), Mora and Vahrson, GIS, hazard map.
\end{abstract}




\section{Introduction}

Latin American and the Caribbean regions are heavily affected by natural disasters. According to a recent hypothesis, the disappearance of the Maya civilization is now believed by historians to be linked to an unusually long and severe drought. Because of its geomorphologic situation and its geographical position, the region is prone to natural events of severe intensity, although experts link the large human and economic cost associated to these events to an extreme vulnerability.

Looking back only to the last 30 years, we can count an average of 32,4 disasters per year in this region, which led to a total of 226.000 fatalities, that is to say about 7.500 per year. Analysis shows that the frequency of disasters seems to rise during the $20^{\text {th }}$ century, although it is possible that this is not connected with a real increase in natural disasters, but rather with the lack of data available for the first half of the century [1].

Obviously all these disasters have meant enormous economic costs for the countries hit, not only linked to the disaster itself but also because of the weak response mechanism. The economic effects involve not only restoration, but also the disruption of economic activities with an immediate impact on the Gross Domestic Product (GDP) growth. Given that this area is exposed to natural risks and the economic resources that can be allocated for civil protection and risk forecasting are limited, the aim of this work is to investigate if any methods exist that could be helpful in gathering better territory knowledge. It will be very important to get an overall view of the territory and its critical points; moreover, these methods should be integrated into a Decision Support System (DSS) to help manage economic resources and efforts in order to maximize the effectiveness of any actions.

Testing the possibility of applying regional methods to forecast landslide susceptibility in large areas, with little effort and starting from a limited amount of data, is a basic step to encourage their diffusion and use. In order to prove that these methods can be useful for DSSs, two opposite case studies were chosen: one in Guatemala, a perfect example of what has been mentioned about the difficult situation in Central America, with little input data and extensive landslide hazards. The other one is located in the Varese district in Italy, a well known site with plenty of data and information that was useful to the authors for rigorous testing of methods; moreover, it is a good chance to apply the Mora and Vahrson method in a European context.

\section{Basin scale methods}

When dealing with landslide risk in such extensive areas, two main problems arise immediately: the lack of data and the small amount of time and money available to accomplish the work. So the authors focused on basin scale methods for landslide risk forecasting. Generally speaking, these methods start from geographic information in order to generate a thematic map that can give a rough evaluation of the risk. Whatever method is chosen, the results will be strongly 
influenced by the quality of the base data. Basically it is impossible to obtain a good result starting with rough data and this issue will be explained in the work. So, the regional method has the power to make a quite good forecasting of events, but it needs careful application and calibration work, since every different kind of terrain will react differently to the same conditions. Although these applications will require validation and a check of rightness, they have a really useful feature: they are totally automatic and the whole work can be carried out by a trained operator and a personal computer with GIS software installed on it. The authors do not suggest totally neglecting the in situ analysis and local studies, but the first step of the work does not need this information, which requires a long time and high costs to be collected. Moreover, the accuracy of the results is really effective and with a good quality to cost ratio, assuming that the model result is a thematic map and is only a good indication of risk and not an absolute evaluation.

\subsection{Types of landslide}

Since analyzing every single kind of landslide that could happen in a large territory is quite impossible, or at least very time consuming and expensive, the authors decided to focus only on shallow landslides, these events being the most common in the study areas. Such events involve only limited zones of terrain, with a moderate thickness, not more than 5 meters, and the moving material is made mainly of surface debris. These landslides are frequent and very dangerous, both because of the starting points, which are not easily determinable, and because of their evolving speed. When referring to shallow landslides usually geologists refer to soil slips and dumps and to debris flow.

The authors chose two different regional methods that are commonly used for regional scale shallow landslide forecasting: Stability Index MAPping (SINMAP) and the Mora and Vahrson method.

SINMAP was developed in 1998 by a team at Utah State University. It works as an extension of ArcGis software, a software by ESRI inc., and it give as a result a map of areas of potential instability and landslide risk. The model uses as input files a DEM of the studied region and a shapefile containing known points of landslide initiation. SINMAP requires the calibration of some parameters based on the information collected in situ. The model is based on an indefinite slope equation that evaluates the safety factor of an area. The equation takes into account a variety of parameters, ranging from the slope and wetness of the terrain to the soil and root cohesion [2].

The Mora and Vahrson method was developed by Mora and Vahrson, and published in TC4, Manual for zonation on seismic geotechnical hazard. This method considers the role of three main factors, morphology, lithology and soil humidity, on landslide susceptibly and two triggering factors: earthquakes and rainfalls. These factors are multiplied together to get a final number indicating the landslide risk level. The Mora and Vahrson method is not widely used in Europe, since it was developed and tested for the Central American situation [3]. 


\section{Guatemala study case}

The first case study chosen is in Guatemala. This country is extremely prone to shallow landslides; moreover, the resources allocated to civil protection are limited, adding a noticeable vulnerability to an already critical situation. Guatemala is located in Central America, just next to the southern border of Mexico, and it is threatened by two types of natural risks: earthquakes and landslides. The country is located at the intersection of three active tectonic plates, the Cocos, the Caribbean and the North American, consequently in the past centuries major earthquakes have destroyed communities and livelihoods. Hurricanes are the other main cause of disasters in Guatemala, provoking great impacts on the agricultural sector and road infrastructures; both earthquakes and hurricanes are triggering causes of debris flows, lahars and landslides. Such events have been reported since the Spanish arrived in Guatemala: the first written documents about big landslides date back to 1541 , when on the $11^{\text {th }}$ September massive rainfalls associated with a tropical hurricane triggered a large landslide that buried the city of Santiago de los Caballeros, which at the time was the seat of the Spanish Government.

Nowadays the situation is still critical, as the population of Guatemala has grown through the centuries the country has undergone heavy deforestation. Because of this landslides are very common, in particular during the rainy season stretching between March and October. Guatemala does not have the large economic resources necessary to sustain landslide research and, in addition, the input data were quite rough, with a low resolution. To evaluate the Guatemala case study others authors' works were studied and their results are now reported. The first work applied SINMAP, the second one Mora and Vahrson. A technical report performed by Rachel Chisolm, from the University of Texas in Austin, applied SINMAP to Guatemala referring results to Hurricane Stan in October 2005 [4].

The DTM used had a 30 second arc resolution and monthly average rainfalls collected by Global Precipitation Climatology Center (GPCC) were the only rainfall information used. Moreover, the author also used a map developed by the Instituto Nacional de Sismologia, Vulcanologia, Meterologia e Hidrologia (INSEVUMEH) that shows the accumulated rainfalls for the 10 day period after the start of Stan.

Unfortunately these data were too rough for a good application of the model and the authors obtained a result, showed in Figure 1, which was inadequate. This map shows the contributing area of each cell, and all the cells have a contributing area of less than ten cells. This is illogical in a country of varied topography, such as Guatemala, and is due to the coarseness of the DEM. The 30 second arc resolution is too rough to see the largest part of the topography variations. This has the effect of smoothing out the terrain, so an accurate analysis could not be made. So, it is concluded that a relationship between altitude, rainfall and landslides exists, as showed by Figure 2 .

Better results were expected with the application of the Mora and Vahrson method. The work was published by Geopetrol SA in "Estudio hidro-geologico 


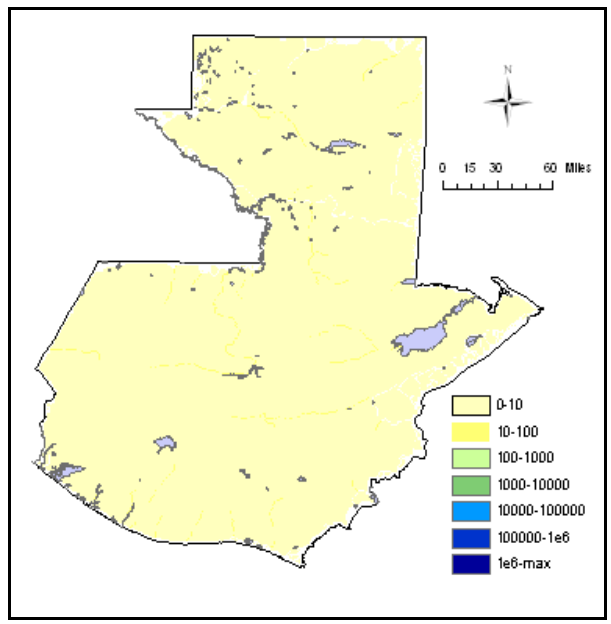

Figure 1: $\quad$ SINMAP contributing area and landslide locations.

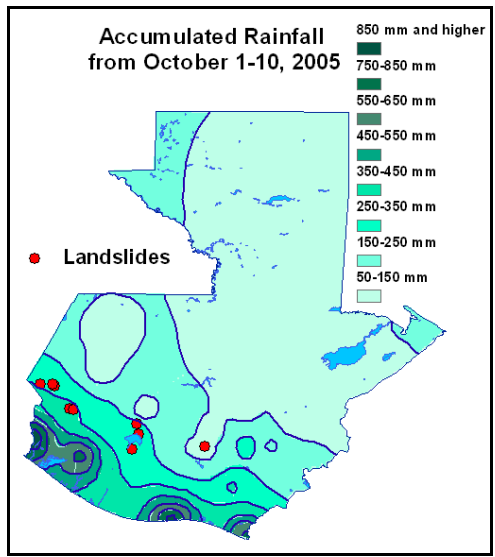

Figure 2: $\quad$ Landslide locations and accumulated rainfall.

para lòa implementacion de un sistema de monitoreo y alerta ante deslizamentos en asentaminetos urbanos del departemento de Guatemala, Centro America". Notice that the investigated area in this study was not the entire country, but only the central region called Zona Metropolitana de Guatemala. These results are more encouraging, mostly because the authors could rely on a slightly better topographic input [5].

Actually the DEM was built up starting from level lines of the national map. Then the method necessitated some lithological parameters as input values, which could be easily extracted from the geological map with little or no influence of scale. It is important to say that in this example earthquakes were neglected as triggering factors, because the authors wanted to focus only on rainfall triggered landslides. The map in Figure 3 represents the area of 
homogenous hazard divided into Low, Moderate, High, Really High. The map in Figure 4 represents the spatial distribution of landslides events in the studied region between 2005 and 2007. It is impossible to make a comparison between the results of the two methods, because of the lack of data from SINMAP. Relying only on Mora and Vahrson, the first thing that requires attention is how the landslide hazard grows moving from north east to south west. This is due to two factors: rainfall intensity, which grows exactly that way, and terrain elevation.

However, the hazard map has only a slightly correspondence with the real distribution of landslides: there is at least one main reason for that. The input DEM was not a high quality one so, starting with the evidence that the greatest

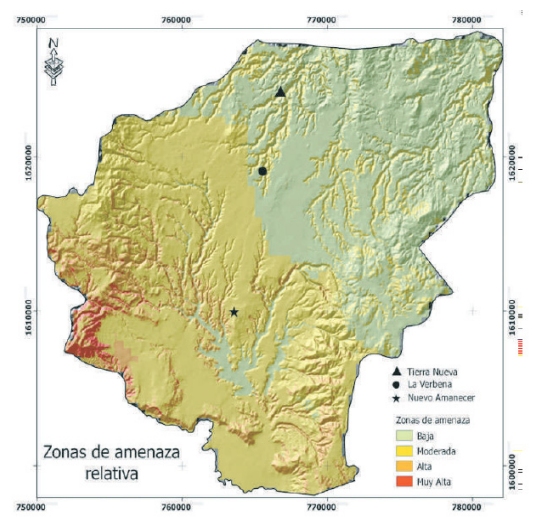

Figure 3: Hazard map landslide location in Zona.

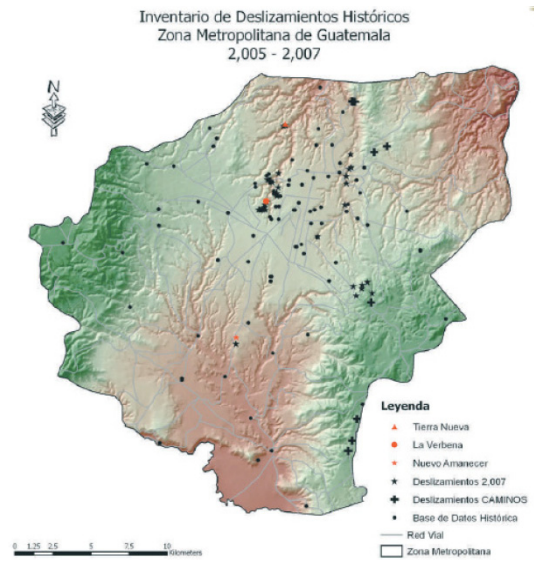

Figure 4: Metropolitana de Guatemala. 


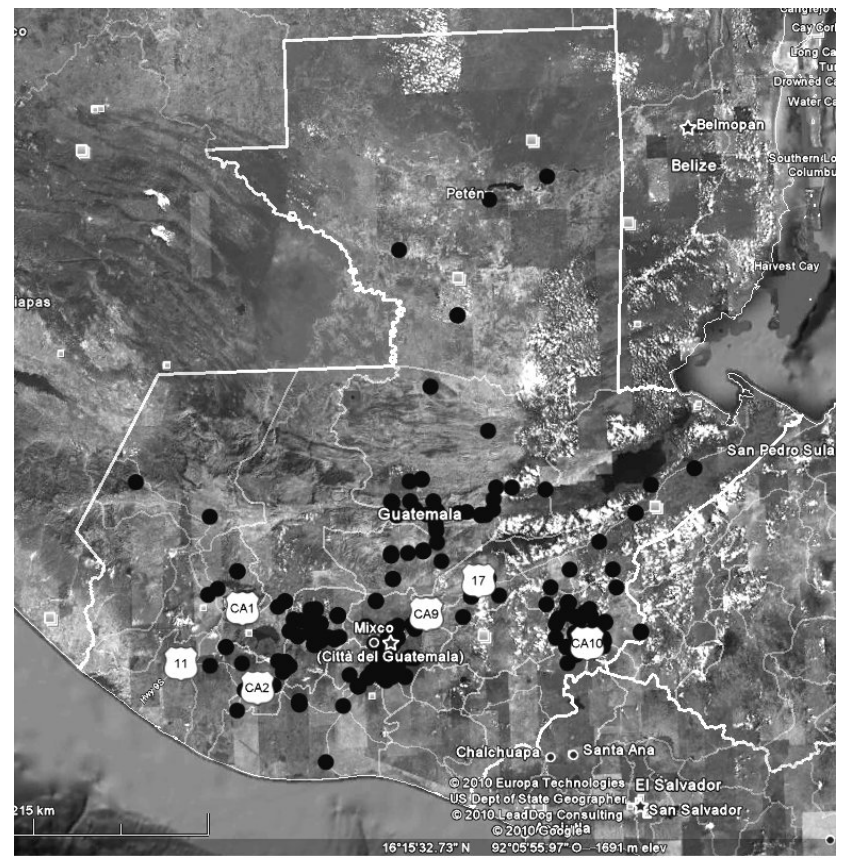

Figure 5: Guatemala landslide locations, black dots.

part of landslides happened in really narrow valleys, the terrain model cannot see them and cannot consider their slope in the calculations. The direct consequence is the impossibility to forecast these events.

It is important to have a database collecting every event that has happened in recent years, because this the paper presents efforts to compile an archive of the many events that have happened in Guatemala in the last ten years; this database is mainly based on many events collected in INSEVUMEH papers [6], which are represented in Figure 5. It is possible to notice that landslides are grouped in the southern part of the country, as was expected. So comparing the literature results with this summarizing map gives an idea of the method's ability to forecast landslides; notice how, while starting form similar data, SINMAP is not able to give a result in Guatemala, while Mora and Vahrson can also make some hazard mapping when input data are rough and with a low resolution. The inventory confirms what has been found by Chilsom, that there is a strong correlation between slope rainfalls and landslides.

\section{The Italian study case}

This paper applies the methods already used in Guatemala to a well known territory in Italy in order to evaluate their reliability. This second case study features a lot of data from previous studies. Moreover, this area is close to the authors' location and they could get directly on the terrain to better understand 
the events in progress. The authors could also compare their results with the Inventario Fenomeni Franosi Italiani (IFFI) database. The IFFI was a big project that had the ambitious objective of summarizing all the Italian landslide events in a georeferenced archive. The zone investigated is the Comunità Montata della Valganna and Valmarchirolo in the Varese district, Lombardia, Northern Italy. The surface is about $55 \mathrm{~km}^{2}$, and it is mainly a mountain area. The terrain altitude varies from $200 \mathrm{~m}$ above sea level to $1100 \mathrm{~m}$. This area is commonly involved in shallow landslides events. The authors applied the Mora and Vahrson method, starting from high quality input data. A 20x20 meters DEM was available and also small-scale geological maps. During data elaborations a problem arose: the Mora and Vahrson parameters are calibrated on the Central American climate, so the evapotranspiration value was not suitable for the Italian climate. The authors decided to adjust the scale of value in order to center it on real observed results. Actually the use of original scale of values would have labeled all zones as maximum value, removing sense from the parameter itself. The result of the elaboration is reported in Figure 6; the shades represent the hazard level: Low, Medium, High and Really High. The same territory has been investigated with SINMAP. In this case the results are also good; the input data were sufficiently precise and the model could work with success. SINMAP produces a thematic map where different colors correspond to different hazard levels, as shown in Figure 7. Making a comparison between the two methods is possible in this case; first of all both the models give good results, the hazardous zones are the same and so are the safe zones. Mora and Vahrson seems to suggest that only a small area is in low hazard zone, while SINMAP labels

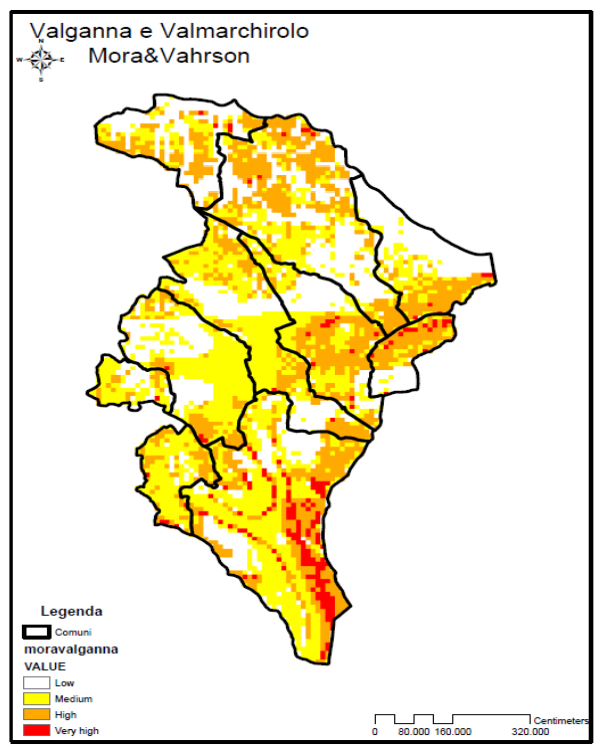

Figure 6: Valganna and Valmarchirolo hazard according to the Mora and Vahrson model. 


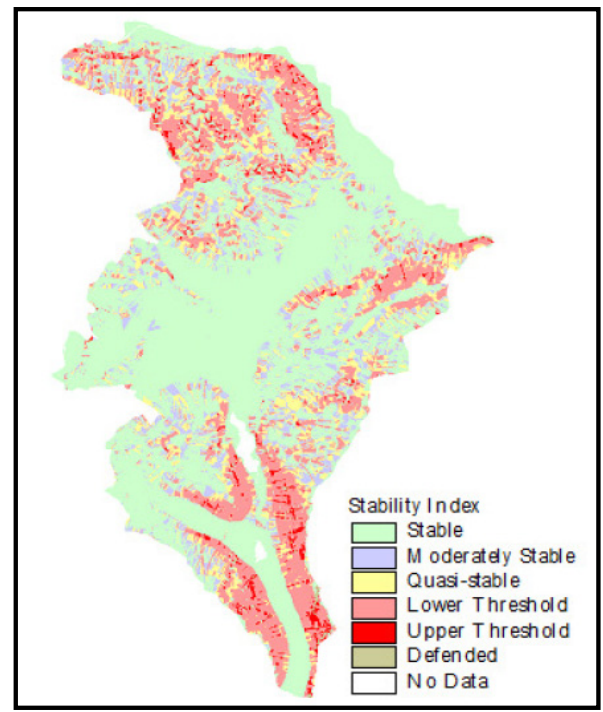

Figure 7: Valganna and Valmarchirolo hazard map according to SINMAP.



Figure 8: $\quad$ IFFI database of slides in Valganna and Valmarchirolo. 
the biggest part of Valganna and Valmarchirolo as stable. This is probably due to a different mapping of results: SINMAP has six levels, while Mora and Vahrson has only four; moreover, the second method is very sensitive to slope, and in all the areas investigated only a marginal fraction is plain. The map in Figure 8 summarizes all the shallow landslides known in the studied zone taken from the IFFI database; it is possible to notice how all the events fall in the most dangerous areas. These areas are logically concentrated in hilly and mountainous zones, since slope is one of, if not the most, influencing factor when mapping landslide hazards. Looking at the SINMAP results it is possible to find a good correlation between calculated risk and real event locations. The model is able to predict that $70 \%$ of the reported landslides lay in hazardous zones. Finally it is clear that both the models give good results, but probably SINMAP is slightly better because it is able to indicate the instable zones, leaving a fair percentage of no risk or safe territory, while in Mora and Vahrson only a small part is marked as Low Risk. Although showed to be easily adaptable to a terrain (the Alps region), the results from this last model were completely different from those used for calibration.

\section{Study case comparison}

Finally, it is possible to make a comparison between the two examples chosen: Guatemala and Varese. The first thing that can be noticed is that the results are strongly influenced by input data. It is really important to have good quality data to apply the model and gather results. In the Guatemala case study the maps are poor and imprecise and despite the efforts of the authors, possible landslides cannot be correctly identified within the hazard zones. This prevents the authors from having the chance to test the methods and evaluate their reliability. Luckily, in the Italian case study, the results demonstrate that both SINMAP and Mora and Vahrson can provide useful indications about slide hazards. It is important to point out that the Italian case study was much smaller than the Guatemalan one, but this has no effect on the Mora and Vahrson model, since the same data used for Valganna and Valmarchirolo are available for the whole of Italy. Unluckily, but logically, SINMAP requires really precise data in order to work; these data need to be collected directly on the terrain. For example, the model needs information about climate and root cohesion, not in terms of a numeric evaluation but as a probability distribution. Moreover, it is strongly conditioned by the landslide triggering point database. These data helps the model to be reliable, but are not easily collectible for large territories, so it is not probable that in the near future they will be available for Guatemala, since they require a huge amount of time and money to evaluate. Mora and Vahrson shows a lower precision, but starts from common data; basically a good DTM is needed and this requires less effort and no in situ analysis. Finally, the scale should be carefully considered: although these methods can be ideally applied to an entire country, the authors suggest choosing a proper area to investigate. The Italian case study has the right extension for methods application; since the results are good we can also expect good reliability on a small scale; in other cases, such as Guatemala 
for example, the low resolution of input data force one to move to a bigger scale, so the resulting map will be more likely to indicate hazard in extensive zones that will require further investigations. It is important to remark that all the models use approximation to describe a complex physical reality and to describe spatial variance of parameters, so they produce results with a limited reliability; however, these approximations are absolutely acceptable in large-scale evaluation, as in the cases analyzed in this paper, and can give a good idea of relative risk in an area.

\section{Conclusions}

This work demonstrates how it is possible to improve safety from landslide hazards, building thematic maps for large territories in a relative quick way. The objective of the authors was to focus attention on the critical situation of the Central American region and the lack of an effective approach to civil protection in that area. The methods applied here prove to give a precious indication about the vulnerability and can be used to rationalize the efforts and the scarce economical resources only in the high risk areas, being an effective DSS for a critical situation, improving effort effectiveness and the response to emergencies. Input data available for any situation will be an active part of the DSS; together with the space scale of results that is needed and the situation in which these models should operate they will determine when it is better to apply Mora and Vahrson and when SINMAP is to be preferred. Nowadays, input data for Guatemala are not as precise as they need to be for the correct application of models, but getting a new DEM with improved resolution is an operation with a reasonable price; it would certainly be more economic than a long in situ campaign. The models themselves can operate a good zoning operation when starting from high quality data and are suitable for the requested work. The Mora and Vahrson method requires more easily collectable data than SINMAP and gives slightly coarser results, but the evidence shows a good benefit-cost ratio. It is important to remember that the Mora and Vahrson method was developed and calibrated on the Central American situation and probably would have also given better results in the Guatemalan case study than in the Italian one, provided that it is possible to get the right data. So, the tools to improve safety and resilience to shallow landslides in Central America exist and are effective, and the authors hope that efforts will be made to improve safety conditions in those critical regions.

\section{References}

[1] Courela P.; Civil Protection and EU-Latin American Relations

[2] Goodwin C.N., Tarboton D.G., SINMAP User's Manual, A stability index approach to terrain stability hazard mapping

[3] Mora, S. and Vahrson, W. (1993). Macrozonation Methodology for Landslide in TC4 Manual for Zonation on Seismic Geotechnical Hazards. 
196 Monitoring, Simulation, Prevention and Remediation of Dense and Debris Flows III

[4] Hazard Determination, Bull. Intl. Ass. Eng. Geology, in press. Chisolm R.; The effect of rainfall on landslides in Guatemala during hurricane Stan, Report for Environmental and Water Resources Engineering, University of Texas at Austin

[5] Geopetrol SA Estudio hidro-geologico para lòa implementacion de un sistema de monitoreo y alerta ante deslizamentos en asentaminetos urbanos del departemento de Guatemala, Centro America pp 15-25

[6] Guatemala. Ministerio de Comunicaciones, Transporte y Obras Públicas. INSIVUMEH. Sección de Hidrología Aplicada, Inventario de los principales deslizamientos ocurridos en la República de Guatemala. 